\title{
ELECTRONIC FILE AVALABLE
}

\author{
UCRL-JC-120364 \\ PREPRINT \\ CoNf-950691--14
}

\section{Normal-Zone Detection in Tokamak Superconducting Magnets with Co-Wound Voltage Sensors}

\author{
Nicolai N. Martovetsky and Michael R. Chaplin
}

This paper was prepared for submittal to the

IEEE Transactions on Magnetics and

The Fourteenth International Conference on Magnet Technology

Tampere, Finland

June 11-16, 1995

June 8, 1995

This is a preprint of a paper intended for publication in a joumal or proceedings. Since changes may be made before publication, this preprint is made available with the understanding that it will not be cited or reproduced without the permission of the author. 


\section{DISCLAIMER}

This document was prepared as an account of work sponsored by an agency of the United States Government. Neither the United States Government nor the University of California nor any of their employees, makes any warranty, express or implied, or assumes any legal liability or responsibility for the accuracy, completeness, or usefulness of any information, apparatus, product, or process disclosed, or represents that its use would not infringe privately owned rights. Reference herein to any specific commercial product, process, or service by trade name, trademark, manufacturer, or otherwise, does not necessarily constihute or imply its endorsement, recommendation, or favoring by the United States Government or the University of California. The views and opinions of authors expressed herein do not necessarily state or reflect those of the United States Government or the University of California, and shall not be used for advertising or product endorsement purposes. 


\section{DISCLAIMER}

Portions of this document may be illegible in electronic image products. Images are produced from the best available original document. 


\title{
Normal-Zone Detection in Tokamak Superconducting Magnets with Co-Wound Voltage Sensors
}

\author{
Nicolai N. Martovetsky, Michael R. Chaplin \\ Lawrence Livermore National Laboratory, Livermore, CA 94550
}

\begin{abstract}
This paper discusses advantages and disadvantages of different locations of co-wound voltage sensors for quench detectlon in tokamak magnets with a cable-in-condult conductor. The voltage sensor locations are analyzed and estimates of the anticipated noise vs. $\mathrm{dB} / \mathrm{dt}$ are derived for transverse, parallel, and self fields. The LLNL Noise Rejection Experiment, also described here, is designed to verify theoretical expectations on a copper cable exposed to these fields that will simulate the tokamak field environment.
\end{abstract}

\section{INTRODUCTION}

In DC superconducting magnets, the detection of a normal zone is done by canceling the inductive signal by using a bridge scheme. This cancellation is necessary since the voltage across the normal zone can be low in comparison with the inductive component of the voltage across the terminals. If not detected and current discharged quickly, a normal zone can cause excessively high temperature and damage the magnet.

This principle of cancellation of the inductive signal is shown in Fig. 1. First, the bridge is balanced and then whenever the resistive component appears in the coil, the galvanometer indicates an imbalance.

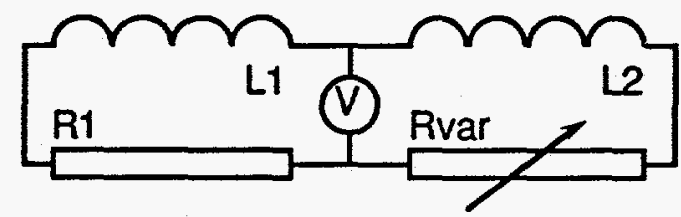

Fig. 1 Bridge scheme for inductive signal compensation

In this scheme $\mathrm{L} 1$ might be a whole magnet, $\mathrm{L} 2$ is an additional coil, co-wound with the conductor or wound separately; or L1 might be part of the coil, L2 is another part, like a pancake or half of the magnet. The important thing is that the signals induced in both coils are proportional to the di/dt. Then it is relatively easy to compensate and cancel the inductive voltage and develop the sensitivity of the detection of the resistive component in the SC magnet at the level of a few millivolts or even better, like tens of microvolts with the total voltage across the coil of several volts.

This principal of cancellation of the induced voltage works even if there are several magnets, and it is still possible to obtain reasonably good resolution in detection of the normal zone with a more elaborate scheme [1].

However, the application of this principle on big tokamak magnets is not straightforward for the following reasons:

Manuscript received June 12, 1995

Nicolai N. Martovetsky, e-mail martovetsky1@linl.gov, Michael R. Chaplin, e-mail mchaplin@ilinl.gov

This work was performed under the auspices of the U.S. Department of Energy by the Lawrence Livermore National Laboratory under contract No. W-7405-Eng-48 and the Princeton Plasma Physics Laboratory under contract number DE-ACO2-76-CH03073.
1. Voltages developed during the cycle across tokamak magnets will be several kilovolts in contrast to several volts in usual DC magnets, which requires much better cancellation of the inductive voltage than in DC magnets.

2. Cable-In-Conduit Conductor (CICC) used in modern tokamak projects has a complicated cabling pattern in comparison with traditional monolithic or cabled conductors used in the past, and does not have easy current redistribution capability.

3. There are many sources of the varying magnetic fields in the magnet system, and current is not varying synchronically in all magnets.

There are alternative approaches to the detection of the normal zone under consideration; like pressure sensors, flow meters at the inlet and outlet of the conduit, and fiber-optic temperature sensors [2].

In this paper, only electrical coil measurements will be the one discussed. We assume that this signal wire is co-wound with the conductor and connected to the one terminal electrically, and that the insulated signal wire goes along the whole length of the conductor between the joints. The voltage is measured between the other end of the signal wire and the second terminal as shown in Fig. 2.

In a tokamak $\mathrm{CICC}$, we must distinguish 3 relatively independent sources of the inductive signal.

1) Transversal component of the extemal varying magnetic field, we will refer to this as $\dot{B}_{1}$.

2) Longitudinal component of the magnetic external field, $\dot{B}_{m}$.

3) Self field of the CICC, $i$.

Feasibility studies were performed on incorporating signal wires into the Tokamak Physics Experiment (TPX) cables. The design of the signal wire is coaxial with a stainless steel or $\mathrm{Cr}-\mathrm{Ni}$ sheath, a copper or $\mathrm{Cr}-\mathrm{Ni}$ core, and mineral insulation $(\mathrm{MgO})$ in the annulus. This type of wire can withstand the reaction heat treatment of the CICC and its normal operating temperatures down to $4 \mathrm{~K}$. The diameter of the signal wire was within $1-1.6 \mathrm{~mm}$.

We will not consider mechanical issues; like motion of the conductors, motion of strands, or unequal and dynamic current redistribution inside the cable. In numerical estimates we will use the TPX magnet parameters.

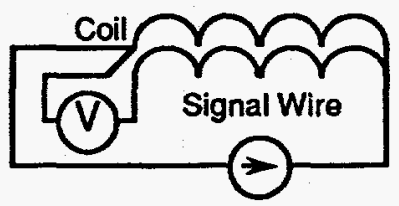

Fig. 2. Schematic of the normal zone detection 


\section{ANALYSIS}

Let us analyze what kind of uncompensated inductive signals we might expect from the signal wires placed in:

I Geometrical center of the CICC.

II. Placed outside the cable (but inside the conduit) in "valleys" of the last stage cabling and therefore twisted with the last stage cable.

III. Signal wire outside the sheath, not twisted around the conductor.

IV. Placed in the first stage of cabling and therefore twisted with the same cabling pattern as all other strands.

V. Placed in the center of the last stage subcable and therefore has the same twist pitch as the last cabling stage.

Let us estimate what order of magnitude of the signal we are looking for. We assume that the system of the normal zone detection should have a resolution of $1 \mathrm{~m}$ of the normal zone. Maximum current density in TPX conductors for example in copper is about $2 \mathrm{e} 8 \mathrm{~A} / \mathrm{m}^{2}$, copper resistivity at $R R R=100$ and in $9 \mathrm{~T}$ is about $6 \mathrm{e}-10$, so $1 \mathrm{~m}$ of the normal zone will cause voltage of $2 \mathrm{e} 8 * 6 \mathrm{e}-10=0.12 \mathrm{~V}$.

\section{A. Signal wire in the Center \\ 1) $\dot{B}_{\perp}$ Effect}

In perfectly homogeneous transverse field, the strand goes symmetrically around the central line, so the area and mangetic flux from one side of the central line is equal to that of the other side of the central line. This simplistically is shown in Fig. 3.

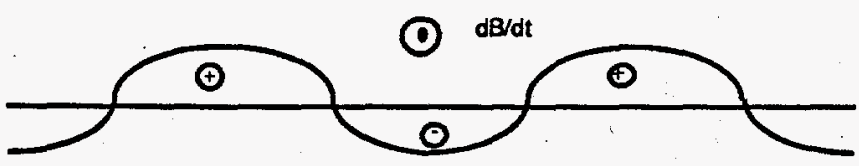

Fig. 3. Schematic of the Bt effect on the induced voltage

The field in the magnet is not homogeneous, however. So, sources of the induced signals will be dependent on the variation of the inhomogeneity of the transverse magnetic field and of the twist pitch. Let us make a rough estimate of the signal which we might expect due to variation of the twist pitch. Suppose we have an average $6.4 \mathrm{~T} / \mathrm{s}$ varying field (maximum for TPX, for example is about $12.8 \mathrm{~T} / \mathrm{s}$ on CS both at start up and at disruption [3]) and discompensation of the areas with positive and negative signal is $5 \%$, the area with positive signals requires a more accurate calculation, but we assume that it is about sinusoidal and area with positive contribution is about;

$$
S_{+}=\frac{r_{a}}{\pi} L \approx \frac{d L}{4 \pi},
$$

where $r_{a}$ is an average distance of the strand from the center line, $L$ length of the conductor, $d$ - diameter of the cable or width if rectangular cross section. We assume that $r_{\mathbf{a}}$ equals to $d / 4, L=600 \mathrm{~m}, d B / d t=6.4 T / s$. So, expected induced signal because of that is:

$$
V=\frac{d L}{4 \pi} B_{t} * 5 \%=\frac{2 e-2 * 0.6 e 3}{4 \pi} * 6.4 * 0.05=0.3 V
$$

which is larger than the normal zone of $1 \mathrm{~m}$ of the conductor.

This does not give us a good feeling of capability to detect a normal zone, as $5 \%$ of the discompensation may be optimistic (specs call usually for $+/-10 \%$ of the consistency of the twist pitch and this is before insertion in a conduit). Also, the field is not uniform in the cable area.

\section{2) $\dot{B}_{\|}$Longitudinal Field Effect}

This is less of a problem for PF coils, but TF coils experience large parallel field pulses, at startup and at the disruption. Cabling pattern is $3 \times 3 \times 3 \times 3 \times 6$. Length of the conductor for the TPX TF magnets is about $1000 \mathrm{~m}$.

Each strand goes into the 5 cabling stages. Each stage of the cable generates electromotive force of:

$$
V=\frac{\dot{B}_{p} \pi r_{i}^{2}}{l_{r}}
$$

per unit length. Here $r_{i}$ is the radius of the subcable center from the center of the cable of the stage $i$ and $l_{p}$ is a twist pitch.

Specifications about twist pitch for different stages of the cabling are in the process, let us assume $40 \mathrm{~mm}, 80 \mathrm{~mm}, 160$ $\mathrm{mm}, 240 \mathrm{~mm}$ and $360 \mathrm{~mm}$ respectively.

Table I shows the voltage generated by different stages of cabling for TPX TF conductor.

Table I

PARALIEL_FIELD INDUCED VOLTAGES IN THE CABLE

\begin{tabular}{|c|c|c|c|c|c|}
\hline \multicolumn{3}{|c|}{ Assume dBpar/dt= 1 T/s } & & & \\
\hline Stage & Strands & lp, mm & $R, \mathrm{~mm}$ & $V(\mathrm{at} 1 \mathrm{~km})$ & $\%$ \\
\hline 0 & 1 & 10 & 0.39 & 0.024 & 8.7 \\
\hline 1 & 3 & 40 & 0.46 & 0.008 & 3.0 \\
\hline 2 & 9 & 80 & 0.80 & 0.013 & 4.6 \\
\hline 3 & 27 & 160 & 1.20 & 0.014 & 5.1 \\
\hline 4 & 81 & 240 & 2.10 & 0.029 & 10.5 \\
\hline 5 & 486 & 360 & 6.55 & 0.187 & 68.1 \\
\hline Total & & & & 0.275 & 100.0 \\
\hline
\end{tabular}

This shows that if average $\mathrm{dB} / \mathrm{dt}$ is $1 \mathrm{~T} / \mathrm{s}$ (for TPX maximum is 7.32T/s at start up, $22.3 \mathrm{~T} / \mathrm{s}$ at disruption [4]). It is already more than 2 times the signal from a $1-\mathrm{m}$ long normal zone. Table I shows an inductive signal generated in individual strand which depends on the transport current [5]:

$$
V=\dot{B} \frac{\pi r^{2}}{2 l}\left(1 \pm \frac{I}{I_{c}}\right) L=1 \frac{3.14 *(0.4 e-3)^{2}}{2 * 10 e-3} 1000=0.025 \mathrm{~V}
$$

It is seen that influence of the last stage is overwhelming. The signal wire in the center is not picking up any inductive signal from the parallel pulsed field. 


\section{3) I; Self Field Effect}

This contribution has to do with changing current and self field. Strands in the cross section go from 0 to max. radius, as one traces them along the length; but the contour between the central signal wire and the strand picks up inductive signal associated with the self field. Let's make an estimate for the strand which goes at half of the radius (half width of the cable) in average along the whole length. Using the following relationship (per unit length of the cable):

$$
V=l \int_{0}^{\mu 2} \dot{B}_{s} d r ; \quad B_{s}=\frac{\mu j r}{2} ; j=\frac{I}{\pi r^{2}}
$$

We can obtain:

$$
V=\frac{\mu l \dot{r}^{2}}{4 \pi R^{2}} L
$$

At $10 \mathrm{kA} / \mathrm{s}$ and $\mathrm{r} / \mathrm{R}=1 / 2$, the induced voltage is about 0.25 $V$. In reality, this value will be even higher. For example, PF1 changes current in $0.08 \mathrm{~s}$ from $8.67 \mathrm{kA}$ to $5.29 \mathrm{kA}$, which gives $42 \mathrm{kA} / \mathrm{s}$, other $\mathrm{CS}$ coils are in the same range[3]. Here $\mathrm{j}$ is a current density, $r$ is the mean radius, $B_{S}$ is self field.

As a conclusion to the location of the signal wire in the center, we see that all three sources of the uncompensated voltage can be very high and exceed the level of the signal we are looking for timely detection of the normal zone. Of course, in some cases, like in plasma disruptions, the whole event takes less than a second, so inductive signals might be filtered out by setting up protection after the voltage is seen for a time which would be a priori longer than the pulse and eddy currents decay. But there is not much time for delays of this kind. As it was mentioned before, all operations altogether, detection of the normal zone, analysis of the signal, and putting the discharge circuits into operation should take about $1 \mathrm{~s}$ overall.

\section{B. Comparison with Other Sensor Locations}

Using this approach and assumptions on the diameter of the cable, cabling pattern, length of the conductor and averaged $\mathrm{dB} / \mathrm{dt}$ and $\mathrm{d} / \mathrm{dt}$ we can compare level of the noise we may expect from the co-wound signal wire in different locations. Results of the analysis is given in Table II.

Table II

SUMMARY OF THE ANALYSES OF THE NOISE IN THE CO-WOUND SIGNAL

\begin{tabular}{|c|c|c|c|c|}
\hline Location" & $\begin{array}{l}\text { Noise from } \\
\dot{B}_{1}=6.4 \mathrm{~T} / \mathrm{s} \\
\mathrm{V}\end{array}$ & $\begin{array}{l}\text { Noise from } \\
\dot{B}_{\|}=1 \mathrm{~T} / \mathrm{s} \\
\mathrm{V}\end{array}$ & $\begin{array}{l}\text { Noise from } \\
I=10^{4} \mathrm{~A} / \mathrm{s}\end{array}$ & Comments \\
\hline $\mathrm{T}$ & 0.3 & 0.28 & 0.25 & $\begin{array}{l}\text { Easiest to cable } \\
\text { in }\end{array}$ \\
\hline II & 0.3 & I.I & 0.75 & $\begin{array}{l}\text { Difícult to } \\
\text { control location }\end{array}$ \\
\hline 111 & 38.4 & 0.28 & 1.2 & $\begin{array}{c}\text { Easiest } 10 \\
\text { install, inspect, } \\
\text { etc. }\end{array}$ \\
\hline IV & 0.0125 & 0.024 & 0.02 & $\begin{array}{c}\text { Difficult to } \\
\text { cable }\end{array}$ \\
\hline $\mathbf{v}$ & 0.1 & 0.08 & 0.08 & $\begin{array}{l}\text { Easy to cable } \\
\text { in }\end{array}$ \\
\hline
\end{tabular}
WIRES AT DIFFERENT LOCATIONS

see text for explanation of the locations
In the POLO experiment [6], 2 signal wires were used for quench detection - a tube in the center and a signal wire at the periphery. The former proved to work better. Analysis in this paper suggests that it probably happened because of the self field effect.

Even though a signal wire embedded in the cable at the triplet stage shows the best flux cancellation, this location has some drawbacks. Incorporation of the signal wire in early stages of the cabling process is not desirable, resulting in handling many relatively short subcables, which increases the cost of the cabling. Also, replacement of one of the regular strands with the signal wires looks intrusive and might affect conductor performance. A litule better approach might be a triplet (or whatever first stage cabling might be) out of signal wires, but it is more difficult than incorporation of the signal wire on last stages.

\section{ANALYSIS CONCLUSIONS}

Detection of the normal zone with a co-wound signal wire does not look impossible, though not any co-wound wire is promising. Signal wire in the first triplet is the best. The signal wire outside the sheath is the worst. Some considerations might make placing of the signal wire into the first triplet difficult. One of those is that a triplet with the signal wire may be deficient in capacity to accept the current from the strand if this strand goes normal. It looks less disturbing if the whole triplet will be replaced with triplet made out of the signal wires.

The second best option is the center of the last stage subcable. Manufacturing consideration might also move the decision towards that last option.

\section{EXPERIMENTAL VERIFICATION}

The LLNL Noise-Rejection Experiment (NRE) [7] will test the noise-rejection capabilities of co-wound wires at different locations that are being considered as the primary quenchdetection sensor for the TPX PF \& TF superconducting magnets. The wires will be used as voltage taps in a copper test coil with a full-size conductor (without a metal conduit) and the same cabling pattern as the TPX PF conductor. The $\mathrm{dB} / \mathrm{dt}$ testing conditions shall include external transverse, parallel, and self (di/dt) fields. Because the noise-coupling issues of signal wires locationed inside a cable are not dependent on temperature or resistivity, this experiment should provide good test results for evaluating the effectiveness of the different signal-wire locations. The cable will use $3600.78 \mathrm{~mm}$ copper stands, and is shown in Fig. 3.

The Noise-Rejection Test Coil (NRTC) will be a layer wound solenoid with 36 turns. A Parallel-Field Coil (PFC) will be wound as a toroid around the NRTC. This assembly is then placed in the bore of a pair of existing TransverseField Coils (TFCs) for testing, as shown in Figure 4. 


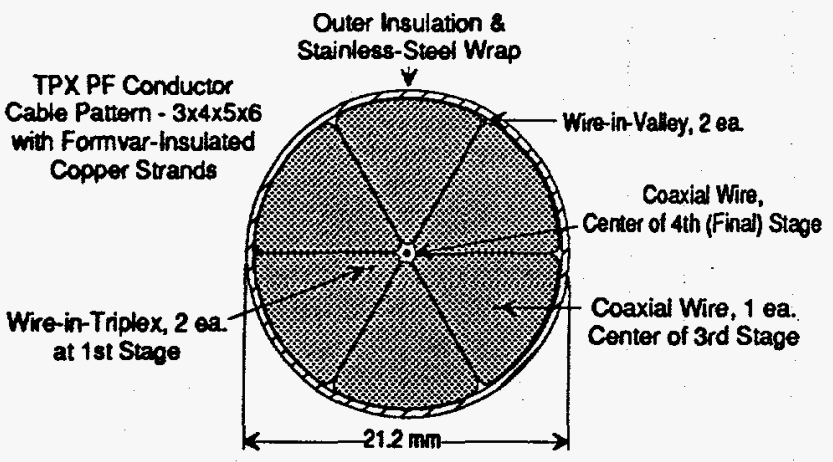

Fig. 3. Cross-section of NRTC Conductor Cable

The current source for this experiment will be the JAERI Inductive-Heating Power Supply on loan to the FENIX Test Facility at LLNL. This power supply consists of a $2000 \mu \mathrm{F}$ capacitor bank with thyristor switches to "ring" the NRE coils individually during the experiment. The capacitor bank can be charged up to $1500 \mathrm{~V}$, and the thyristors can deliver current pulses up to $1000 \mathrm{~A}$. The expected noise parameters for each source are shown in Table III.

All voltage sensors will be terminated with the copper strands into a clamped, copper block at one end of the NRTC. At the other end the copper strands will be terminated into a similiar copper block, but with the voltage sensor wires extracted just before the block. These sensor wires will then be paired with wires from the adjacent copper block and routed to the data acquisition system. In addition to these cowound sensors, 2 pairs of conventional voltages taps will be paired from the copper blocks to measure the full inductive voltage that will appear across the NRTC. The NRTC was wound in early June, 1995; and the experiment should be completed in July, 1995.

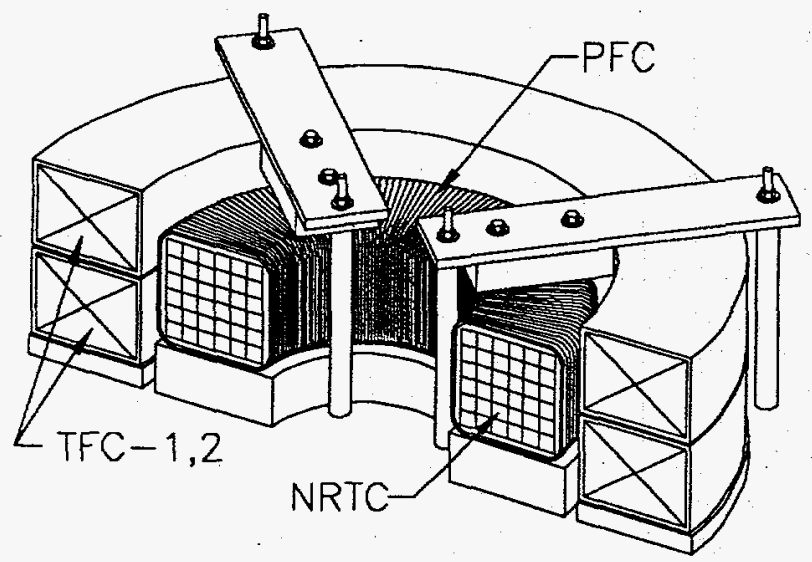

Figure 4 : NRE Coil Configuration
Table III.

NOISE SOURCE SUMMARY

\begin{tabular}{|c|c|c|c|c|}
\hline $\begin{array}{c}\text { Field } \\
\text { Orientation }\end{array}$ & Noise Source & $\begin{array}{c}\text { B } \\
\text { MAX }\end{array}$ & $\begin{array}{c}\text { dB/dt } \\
\text { MAX }\end{array}$ & $\begin{array}{c}\text { Induced } \\
\text { VNRTC }\end{array}$ \\
\hline $\begin{array}{c}\text { 2-Coil } \\
\text { Transverse } \\
\text { (TFC1 \& 2) }\end{array}$ & Pulsed 20 Hz. & $0.14 \mathrm{~T}$ & $18.2 \mathrm{~T} / \mathrm{s}$ & $108 \mathrm{~V}$ \\
\hline $\begin{array}{c}\text { Parallel } \\
\text { (PFC) }\end{array}$ & Pulsed 114 Hz. & $0.9 \mathrm{~T}$ & $>60 \mathrm{~T} / \mathrm{s}$ & na \\
\hline $\begin{array}{c}\text { Self (di/dt) } \\
\text { (NRTC) }\end{array}$ & Pulsed $166 \mathrm{~Hz}$ & $0.08 \mathrm{~T}$ & $>60 \mathrm{~T} / \mathrm{s}$ & $500 \mathrm{~V}$ \\
\hline
\end{tabular}

\section{ACKNOWLEDGEMENTS}

The authors would like to thank J. H. Schultz at MIT and J. Zbasnik at LLNL for their contributions to this work; Mark Fowler, Andy Hinz, and Nate Liggins at LLNL for their work on the experiment; and JAERI for allowing LLNL to use their power supply to perform this experiment.

\section{REFERENCES}

[1] J.M. Pfotenhauer, F. Kessler, and M.A. Hilal, "Voltage Detection and Magnet Protection," IEEE Trans. on Applied Superconductivity, Vol.3, No.1,p 273, 1993

[2] M.R. Chaplin, W.V. Hassenzahl, and J.H. Schultz, "Quench Detection and Instrumentation for the Tokamak Physics Experiment Magnets," 15th IEEE Sym. on Fusion Engr., Vol.2, pp 802, 1993

[3] P.W. Wang, "12 V Startup with a Maximum Field Null at the Breakdown for TPX," TPX Doc.\# 14-940627. MIT-PWang-01, PPPL, June, 1994

[4] A.L. Radovinsky, "Max. Field \& Time Derivatives in the TPX TF Coils during Plasma Startup \& Plasma Disruption, an Update," TPX Doc.\# 13-940725-MITARadovinsky-01, PPPL, July, 1994

[5] E.Yu. Klimenko, N.N. Martovetsky, and S.I. Novikov, "Transient Field Effects in the Superconducting Coils of the T-15 Tokamak during Disruptions of the Plasma Current," Sov. Phys. Tech. Phys. 30(6), June, 1985, p 614

[6] R. Heller, and the POLO Team, "Results and Preliminary Evaluations of the Stability Limit of the POLO Model Coil," KfK Memorandum, Karlsruhe, FRG, November 10, 1994

[7] M.R. Chaplin, "Noise-Rejection Experiment for TPX Q.D. R\&D, Rev.1," TPX Doc.\# 13-941110-LLNLMChaplin-01, PPPL, November, 1994 